\title{
Políticas públicas de habitação e o programa de aceleração do crescimento: análise das intervenções no estado do Rio de Janeiro*
}

\author{
Andreza Aparecida Franco Câmara ${ }^{1}$
}

\section{Resumo}

O objetivo deste artigo é examinar as políticas públicas habitacionais implantadas pelo Programa de Aceleração do Crescimento (PAC) e as intervenções de urbanização em cortiços e favelas no Estado do Rio de Janeiro. Na primeira parte do trabalho, será analisada a questão fundiária após a promulgação da Constituição de 1988 e do Estatuto da Cidade, bem como a inclusão do tema regularização fundiária no Fórum de Assuntos Fundiários criado pelo Conselho Nacional de Justiça. Discute-se também a territorialização dos investimentos na política habitacional implementada pelo PAC da habitação, promovendo o processo de inclusão social desenvolvido pelo Governo Federal ao executar sua política nacional de urbanização de favelas promovendo, dentre outras medidas, regularização fundiária, com cooperação das administrações estadual e municipal através de fontes obtidas pelos agentes envolvidos na pesquisa. Finalmente, serão estudadas as principais intervenções históricas realizadas na região metropolitana do Rio de Janeiro, comparando-as com as ações já implantadas pelo PAC, refletindo sobre os instrumentos de regularização fundiária utilizados no PAC com o propósito de garantir o direito à moradia digna nas comunidades. Concluí-se que, através dos projetos de urbanização de assentamentos precários inseridos no PAC, contemplaram-se ações, obras e serviços visando proporcionar a superação das condições de precariedade dos assentamentos escolhidos, incorporando-os à cidade formal, com abordagem das questões urbana, habitacional, fundiária, social e ambiental. Todavia, para evitar a

\footnotetext{
* Artigo recebido em: 27/06/2011

Artigo aprovado em: 18/07/2011

1 Professora Assistente do Curso de Direito da Universidade Federal Rural do Rio de Janeiro, Instituto Três Rios - UFRRJ/ITR. Doutoranda no Programa de Pós-Graduação em Sociologia e Direito da Universidade Federal Fluminense - UFF. Mestre em Direito da Cidade pela Universidade do Estado do Rio de Janeiro - UERJ.
} 
formação de novas ilegalidades, deve-se pensar em um conjunto de medidas econômicas, tributárias e tarifárias para subsidiar os novos custos transferidos para os moradores assistidos.

Palavras-chave: Programa de Aceleração do Crescimento. Regularização fundiária. Estatuto da Cidade. Políticas públicas habitacionais.

\section{Introdução}

O interesse pelo tema que se pretende estudar neste artigo científico é despertado pelas novas orientações nas "políticas públicas habitacionais" com a inclusão, a partir de 2007, do tema em um dos eixos do Programa de Aceleração do Crescimento - PAC, a urbanização de assentamentos precários ganha nova projeção.

As grandes mazelas sociais atacadas pelo programa foram a urbanização dos assentamentos informais, reforçando o reconhecimento do direito à cidade e à moradia digna, especialmente da população de baixa renda. Garantias essas já definidas com a Constituição da República de 1988 e disciplinadas em 2001 com a vigência da Lei $\mathrm{n}^{\circ}$. 10.257, denominada Estatuto da Cidade. Como observa Edésio Fernandes, "a Constituição de 1988 criou um direito coletivo novo, qual seja, o direito ao planejamento urbano"2. Assim sendo, o tema que será desenvolvido refere-se à aplicação da desapropriação judicial como instrumento urbanístico de regularização fundiária aplicada no PAC da habitação.

O Estatuto da Cidade representa um grande avanço para a execução das políticas públicas e do direito urbanístico ao regular o uso da propriedade urbana em prol do bem coletivo, da segurança e do bem-estar dos cidadãos, bem como do equilíbrio ambiental. A propriedade privada passa a ter limites e restrições em face às finalidades públicas a que se submete. A reordenação do desenvolvimento das cidades e as novas diretrizes adotadas, com vistas à cooperação entre os governos,

2 FERNANDES, Edésio (Org.). Direito urbanístico e política urbana no Brasil. Belo Horizonte: Del Rey, 2001. p. 22. 
a iniciativa privada e os demais setores da sociedade, estimulando a participação popular na formulação e execução dos projetos de desenvolvimento urbano são medidas previstas na norma estatutária.

Com a criação do Ministério das Cidades em 2003 visando à urbanização de assentamentos ilegais e informais, o saneamento ambiental e a regularização fundiária, logo após, em 2005, foi editada uma série de medidas governamentais que integram o Sistema (SNHIS) e Fundo Nacional de Habitação de Interesse Social (FNHIS). A partir do ano 2006, foi disponibilizado o valor de um bilhão de reais para o FNHIS iniciar a sua operação. Grande parte desse valor destinou-se à implementação de projetos de urbanização de assentamentos precários, objeto do nosso estudo.

No mesmo ano, o Ministério das Cidades encomendou ao Centro de Estudo das Metrópoles do Centro Brasileiro de Análise e Planejamento - CEM/CEBRAP - um estudo para melhor quantificar, caracterizar e localizar o problema de favelização das cidades brasileiras, sendo possível localizar as principais áreas para a execução de ações integradas em habitação, saneamento e inclusão social.

Após estudos preliminares, foram contemplados os municípios integrantes das regiões metropolitanas de Belém, Fortaleza, Recife, Salvador, Rio de Janeiro, Belo Horizonte, São Paulo, Campinas, Baixada Santista, Curitiba e Porto Alegre, além dos municípios da região integrada do entorno do Distrito Federal e outras áreas de grande porte, cuja população total seja superior a cento e cinquenta mil habitantes ou que, por sua atividade econômica ou infraestrutura logística, possu- 
am raio de influência regional ${ }^{3}$. A distribuição de recursos também seguiu a proporção da dimensão da precariedade habitacional em cada região, admitindo a "territorialização da governança".

\section{A questão fundiária na constituição federal de 1988 e no estatuto da cidade}

A promulgação da Constituição Federal em 1988 laureou o longo processo de democratização do país iniciado, ainda, no final dos anos 1970. Contudo, somente por meio da Emenda Constitucional $n^{\circ}$. 26/2000, o direito fundamental à moradia foi elevado à condição de direito humano positivado, sendo acolhido pela legislação interna brasileira e cabendo ao Estado protegê-lo e implementá-lo através de leis e políticas públicas habitacionais. O processo de democratização pelo qual passou o país consagrou uma reflexão profunda sobre a integração socioespacial dos assentamentos ilegais e precários com a cidade formal, tanto no plano jurídico quanto no plano social.

Por meio dos movimentos sociais urbanos, o capítulo constitucional sobre a política urbana (arts. 182 e 183) e o Estatuto da Cidade reconheceram que a pro-

\footnotetext{
3 Os recursos destinados pelo PAC - Urbanização de Assentamentos Precários - dividem-se em dois grandes grupos, sendo eles os recursos fiscais, consignados no Orçamento Geral da União - OGU, repassados aos estados, Distrito Federal e municípios, com caráter não oneroso, sob forma de transferência obrigatória da União, mediante assinatura de Termos de Compromisso firmados com a CAIXA, como mandatária da União. Incluídos nesses termos os recursos do Fundo Nacional de Habitação de Interesse Social - FNHIS. A outra fonte de custeio é oriunda dos recursos do Fundo de Garantia do Tempo de Serviço - FGTS ou do Fundo de Amparo ao Trabalhador - FAT, repassados aos estados, Distrito Federal e municípios com caráter oneroso, sob forma de financiamentos, mediante assinatura de contratos de empréstimo firmados com a CAIXA ou BNDES, como agentes financeiros.

Além dos recursos da União, compõem os investimentos as contrapartidas dos estados, Distrito Federal e municípios, que podem se apresentar sob a forma de recursos financeiros, bens ou serviços economicamente mensuráveis.

4 CAZELLA, Ademir A.; BONNAL, Philippe; MALUF, Renato S. (Org.). Agricultura familiar: multifuncionalidade e desenvolvimento territorial no Brasil. Rio de Janeiro: Mauad X, 2009. p. 82.
} 
priedade e a cidade devem exercer uma função social, conforme Ermínia Maricato adverte: "É do conhecimento da realidade urbana que emergirão os novos padrões de urbanização e uma nova ordem legal extensivos a toda a cidade e a todos os cidadãos" ${ }^{\prime}$, conferindo ao poder local um papel importante na elaboração e aplicação das políticas públicas de desenvolvimento urbano.

O Estatuto da Cidade constitui um marco histórico para a política urbana já que estabelece instrumentos de intervenção na cidade e aboliu o modelo tradicional-tecnocrático, adotando mecanismos mais adequados ao atendimento das necessidades da parcela da população que ocupa o espaço formal da cidade. O Estatuto da Cidade possui programas de regularização fundiária dos assentamentos considerados irregulares ou clandestinos. O objetivo final é a democratização do acesso à moradia formal e ao solo urbano ${ }^{6}$.

De acordo com a mens legis constitucional, o Estatuto da Cidade encontra a matriz de referência para o planejamento urbano. O objetivo, portanto, é garantir o cumprimento da função social da cidade e da propriedade urbana, estabelecendo normas de ordem pública e interesse social que regulem o uso da propriedade urbana em prol do bem coletivo, da segurança e do bem-estar da coletividade. Diante do exposto, parece correta a posição de Dallari ao defender que antes da Consti-

5 MARICATO, Ermínia. Metrópole na periferia do capitalismo: desigualdade, ilegalidade e violência. São Paulo: Hucitec, 1996. p. 22.

6 SUNDFELD, Carlos Ari. O estatuto da cidade e suas diretrizes gerais. In: DALLARI, Adilson; FERRAZ, Sérgio (Org.). Estatuto da cidade - comentários à Lei Federal 10.257/2001. São Paulo: Malheiros, 2003, p. 52. A necessidade de uma ordem urbanística popular é afirmada diretamente pelo art. $2^{\circ}$, XIV, ao impor como diretriz "o estabelecimento de normas especiais de urbanização, uso e ocupação do solo e edificação" que levem em conta a situação socioeconômica da população. A especialidade dessas normas tem um objetivo definido: permitir a "regularização fundiária e urbanização de áreas ocupadas por população de baixa renda”. A mesma orientação parece estar implícita no inciso XV, quando exige a "simplificação da legislação" com o fim de reduzir os custos da urbanização, ampliando a oferta de lotes e unidades habitacionais.

A exigência de um ordenamento que conduza à regularização fundiária e urbanística das ocupações populares existentes introduz um condicionante novo e transformador em nosso direito urbanístico. Até então a incompatibilidade entre as ocupações populares e a ordem urbanística ideal tinha como consequência a ilegalidade daquelas (sendo a superação desse estado um dever dos responsáveis pela irregularidade - isto é, dos próprios ocupantes)". 
tuição Federal, o Plano Diretor tinha uma função técnico-instrumental, visando à "racionalidade", à "economicidade" e à "eficiência" da Administração Pública. A partir de 1988, esse instrumento passa a ser caracterizado por uma substancial alteração - quanto ao conteúdo, sua abrangência engloba importantes diretrizes, dentre elas a definição de propriedade imobiliária: [...] Entre todos esses instrumentos de planejamento, merece especial destaque o Plano Diretor, em função de uma radical alteração de sua concepção, acarretada pela posição estratégica que lhe foi conferida pela Constituição Federal de 1988".

Embora o acesso à propriedade e à moradia durante anos, aliado à disponibilidade de serviços urbanos colocados para a população citadina, levasse a estabelecer uma lógica cruel entre a dinâmica imobiliária capitalista destinada para as regiões nobres e a conexão entre o padrão de desigualdades sociais, nesse sentido, critica Otília Arantes a nova "requalificação urbana". . Não podemos correr o risco de tornar a propriedade como um ativo financeiro, resultado de uma política internacional de hegemonia neoliberal que nega a moradia como direito humano fundamental, como adverte Raquel Rolnik no Seminário Nacional Estatuto da Cidade +10 anos $^{9}$ em que busca estratégias para o futuro das cidades.

O fenômeno de segregação urbana torna-se mais um produto derivado das leis de mercado que o resultado da recusa, por parte das autoridades públicas, do reconhecimento oficial da existência dos bairros informais. A solução do mercado originou outras formas de exclusão que apenas fizeram aumentar o círculo de informalidade, agora concentrado nas regiões cada vez mais periféricas, insalubres

DALLARI, Adilson Abreu. Instrumentos da política urbana. In: In: DALLARI, Adilson; FERRAZ, Sérgio (Org.). Estatuto da cidade - comentários à Lei Federal 10.257/2001. São Paulo: Malheiros, 2003, p. 77-78.

8 ARANTES, Otília Beatriz Fiori et al. Urbanismo em fim de linha e outros estudos sobre o colapso da modernização arquitetônica. São Paulo: EDUSP, 1998, p. 49.

9 ROLNIK, Raquel. Seminário Nacional Estatuto da Cidade + 10 anos, 2011. Disponível em: <http://escadaedesenvolvimento.wordpress.com/2011/02/07/seminario-nacional-\%E2\%80\%9Cestatuto-da-cidade-10-anos-avancos-e-desafios-da-politica-urbana-e-dos-planos-diretores-participativos>. Acesso em 13 jul. 2011. 
e/ou ecologicamente precárias das cidades. Nesse ponto, existem altos índices de informalidade fundiária das cidades brasileiras ${ }^{10}$.

A precariedade jurídica do acesso ao solo nesses assentamentos sempre serviu como justificativa, não somente para as expulsões arbitrárias, mas também para a ausência de serviços públicos adequados nesses espaços. A insegurança fundiária também limitou o investimento dos moradores em suas casas e em seus bairros. A regularização fundiária se manifesta, assim, como um elemento imprescindível para se materializar o direito à moradia, integrando, aliás, esse direito específico ao leque de direitos que constitui o direito à cidade.

Após a promulgação do Estatuto da Cidade, medidas governamentais foram implementadas para consolidar a regularização fundiária como uma das principais diretrizes da política urbana no Brasil, dentre elas destaca-se o Programa de Aceleração do Crescimento.

${ }^{10}$ Segundo dados obtidos pelo IBGE no ano de 2002 os municípios mais populosos têm maior preocupação com a questão habitacional no Brasil. A MUNIC pesquisou, junto às prefeituras, a administração e a detecção de carências habitacionais, investigando especificamente a existência ou não de órgãos habitacionais específicos ou de cadastros de famílias interessadas em programas habitacionais, bem como o tipo de programa realizado, tais como a construção de unidades habitacionais, a oferta de terrenos, a urbanização de assentamentos, a regularização fundiária, a oferta de material de construção ou a melhoria de cortiços. Dos municípios pesquisados constatou-se que em $37 \%$ deles havia órgão habitacional específico e em $68,2 \%$ cadastro das famílias interessadas em programas nesta área. Entre os municípios mais populosos do Brasil e nas regiões Sul e Centro-Oeste foram encontradas as maiores proporções de municípios com cadastro e com órgãos habitacionais. A construção de casas foi a ação habitacional mais empregada pelas prefeituras. Em 2002, as prefeituras de 61\% dos municípios brasileiros declararam ter executado algum tipo de ação habitacional. Em 2002, entre os seis tipos de políticas habitacionais implementados pelas prefeituras e registrados pela MUNIC, a construção de unidades foi a mais empregada, em todas as Grandes Regiões. Já os programas urbanização de assentamentos e regularização fundiária aparecem em proporções mais elevadas nos municípios mais populosos: $72,7 \%$ das cidades com mais de 500 mil habitantes urbanizaram assentamentos e 63,6\% delas implementaram regularização fundiária. Disponível em: <http:// www.ibge.gov.br/home/presidencia/noticias/noticia_visualiza.php?id_noticia=345>. Acesso em 13 jul.2011. 


\section{0 foco do conselho nacional de justiça em relação aos assuntos fundiários}

O tema contemplado no presente artigo (a regularização fundiária urbana) encontra-se sob foco do Conselho Nacional de Justiça (CNJ) por meio da Resolução $\mathbf{n}^{\circ}$ 110, de 6 de abril de 2010, que institui o Fórum de Assuntos Fundiários ${ }^{11}$. $\mathrm{O}$ fórum destina-se ao monitoramento das ações e à resolução de questões que tenham por objeto assuntos de natureza fundiária, conflituosas ou não, que possam colocar em risco a segurança no campo e nas cidades ou exijam ações concretas para assegurar o acesso à moradia digna e à distribuição da propriedade rural.

A Resolução do CNJ estabelece, dentre as suas prioridades, a realização de medidas concretas e ações coordenadas com vistas ao combate da violência no campo e nas cidades, à regularização fundiária, à pacificação social, à garantia do direito de propriedade e da posse, ao respeito ao Estado de Direito, bem como à defesa do direito à moradia digna.

Merece destaque a redação do art. $2^{\circ}$ da Resolução $n^{\circ}$. 110/2010 quando fixa competência para o monitoramento das ações judiciais de desapropriação por interesse social, para fins de reforma agrária e para fins de reforma urbana, das ações e incidentes judiciais, inclusive de natureza criminal, relacionados à sua implantação, assim como propor medidas concretas e normativas voltadas à modernização de rotinas processuais, à organização, à especialização e à estruturação das unidades judiciárias com competência sobre as áreas de atuação definidas nos incisos anteriores, podendo ainda propor medidas concretas e normativas destinadas à prevenção de conflitos judiciais e à definição de estratégias nas questões agrárias, urbanas e habitacionais e elaborar estudo e proposição de outras medidas consideradas pertinentes ao cumprimento do objetivo do Fórum de Assuntos Fundiários, inclusive para o aprimoramento da legislação pertinente, também visando à solução, à prevenção de conflitos e à regularização das questões que envolvam o tema.

\footnotetext{
${ }^{11}$ Resolução $n^{\circ}$. 110, 6 de abril de 2010. Institucionaliza, no âmbito do Conselho Nacional de Justiça, o Fórum de Assuntos Fundiários, de caráter nacional e permanente, destinado ao monitoramento dos assuntos pertinentes a essa matéria e à resolução de conflitos oriundos de questões fundiárias, agrárias ou urbanas.
} 


\section{A territorialização dos investimentos na política habitacional do PAC}

A discussão envolve um dos conflitos urbanos e sociais que permeiam também a sociedade pós-moderna ${ }^{12}$ : o uso adequado do solo e a moradia legalizada e digna, resultado dos processos de decisão do poder local e central a partir do modelo de gestão sobre os "territórios usados", compreendendo o processo político de escolha de certa técnica ou ação para a formação das relações socioespaciais ${ }^{13}$. Território é aqui compreendido como um espaço de referência cultural com "[...] significado atribuído por um dado grupo ou segmento social", inserindo-se "[...] no campo dos processos de identidade societária, na condição de referente de formas de consciência do espaço, e mesmo de autoconsciência grupal”, segundo Moraes ${ }^{14}$.

Corroborando essa noção, Bertha Koiffmann Becker define território e territorialidade ${ }^{15}$ :

[...] a) O território é o espaço da prática. Por um lado, é um produto da prática espacial: inclui a apropriação de um espaço, implica a noção de limite - um componente de qualquer prática -, manifestando a intenção de poder sobre uma porção precisa do espaço. Por outro lado, é também um produto usado, vivido pelos atores, utilizado como meio para sua prática (Raffestin, 1980); [...]

c) A territorialidade manifesta-se em todas as escalas, desde as relações pessoais e cotidianas até as complexas relações sociais. Ela se fundamenta na identidade e pode repousar na

${ }^{12}$ Um conceito controverso entre os pensadores é o de pós-modernidade. Define-se a pós-modernidade como sendo o momento histórico no qual se constituiu uma crítica à modernidade, particularmente nos campos da arte e da produção do conhecimento acadêmico, estabelecendo-se um debate caracterizado como pós-modernismo, que é orientado em torno do repensar e da superação de alguns preceitos modernos.

${ }^{13}$ SANTOS, Milton. Técnica, espaço tempo: globalização e meio técnico científico informacional. São Paulo: Hucitec, 1994.

${ }^{14}$ MORAES apud CAZELLA, Ademir A.; BONNAL, Philippe; MALUF, Renato S. (Org.). Agricultura familiar: multifuncionalidade e desenvolvimento territorial no Brasil. Rio de Janeiro: Mauad X, 2009. p. 28.

${ }^{15}$ BECKER, Bertha Koiffmann. Novas territorialidades na Amazônia: desafio às políticas públicas. Boletim do Museu Paraense Emilio Goeldi: ciências humanas. Belém, v. 5, n. 1, p. 17-23, jan./abr. 2010. Disponível em: <www.museu-goeldi.br/editora/bh/artigos/.../ dossie_novas(becker).pdf $>$. Acesso em: 23 fev. 2011. 
presença de um estoque cultural que resiste à reapropriação do espaço, de base territorial;

d) A malha territorial vivida é uma manifestação das relações de poder, da oposição do local ao universal, dos conflitos entre a malha concreta e a malha abstrata, concebida e imposta pelos poderes hegemônicos.

Os critérios adotados para a seleção dessas áreas foram, inicialmente, a existência de grandes complexos de favelas. Foram compreendidas como grande porte as intervenções que envolvem investimentos superiores a dez milhões de reais, bem como a articulação e integração no território, cujas áreas de abrangência e execução envolveram mais de um agente institucional - estado e município ou mais de um município. Os projetos selecionados deveriam apresentar propostas que contivessem a participação de outro ente político, visassem à redução de danos ambientais causados por assentamentos irregulares em áreas de proteção ambiental ou em zonas de especial interesse social; além daqueles que eliminariam os gargalos na infraestrutura logística do país, com o aproveitamento do patrimônio da União, e o complemento das obras já iniciadas.

Outra forma de seleção foi a anual, que ocorreu por meio de chamada pública para regiões de menor porte, desde que a área de intervenção fosse ocupada por, pelo menos, $60 \%$ (sessenta por cento) das famílias com renda de até três salários mínimos, ocupada há mais de cinco anos; ou que estivesse localizada em situação que configurasse risco, insalubridade ou fosse objeto de legislação que proibisse sua utilização para fins habitacionais.

A infraestrutura tornou-se tão relevante que, em 11 de fevereiro de 2011, o Governo Federal alterou as regras do Programa Minha Casa, Minha Vida por meio do agente financiador Caixa Econômica Federal, condicionando a liberação para financiamento de imóveis do programa mediante a comprovação da realização de obra de infraestrutura, o que ficou conhecido na mídia como "asfalto na porta", segundo Feldmann e Bié. Contudo, em 28 de fevereiro do mesmo ano, a Caixa Econômica Federal decidiu adiar as medidas para julho após pressões em todo o País e uma reunião ocorrida em Brasília no dia 25 do mesmo mês, com uma comissão de deputados federais. 
O critério adotado pelo governo do estado do Rio de Janeiro, com parceria da União e prefeituras municipais para a seleção das comunidades foi a redução de danos ambientais causados por esse assentamento irregular, que se deu parcialmente em área de proteção ambiental e zona de especial interesse social, revelando o conflito socioambiental e urbano colocado em razão da injustiça ambiental e territorial aos grupos sociais de trabalhadores e populações de baixa renda.

Esse cenário urbano faz parte da observação e do estranhamento dos contrastes e transformações vividos cotidianamente que estimularam a construção de um problema de investigação que busca compreender o local articulado a processos globais de mudança social. Ao se materializarem no lugar, interagem e conflitam com relações de poder, práticas econômicas, sistemas classificatórios e representações previamente existentes e produzem novas significações sobre o território.

A denominação de favela ${ }^{16}$ como categoria de acusação atribuída em geral por aqueles que não habitam este lugar é reelaborada pelos moradores de algumas comunidades que habitam os territórios que sofreram a intervenção do $\mathrm{PAC}^{17}$, valorizando, dessa forma, os sentimentos de pertencimento e identidade.

Entende-se que há simetria entre Programa de Aceleração do Crescimento - PAC da habitação com o Programa Favela-bairro, criado pela prefeitura da

${ }^{16}$ VALLADARES, Lícia do Prado. A invenção da favela: do mito de origem à favela.com. Rio de Janeiro: FGV, 2005. p. 26. Segundo Valladares, a categoria favela, no imaginário social, designa "[...] um habitat pobre, de ocupação ilegal e irregular, sem respeito às normas e geralmente sobre encostas".

${ }^{17}$ Comunidade é uma categoria nativa, muito utilizada na atualidade, sobretudo na cidade do Rio de janeiro para referir-se a populações ou núcleos habitacionais de baixa renda. O termo comunidade passou a ser utilizado, sobretudo pelos moradores dessas áreas em substituição ao termo carregado de valores pejorativos contidos no termo favela. Na definição clássica da teoria sociológica, o termo comunidade refere-se a um agrupamento de pessoas unidas por laços morais rígidos e crenças comuns. Diversos autores têm questionado a comprovação empírica desses elementos em agrupamentos identificados como tal. Contudo, novas definições têm procurado adequar o termo às realidades empíricas observadas. Nesse sentido, faço uso da definição de comunidade como redes de laços interpessoais que proporcionam sociabilidade, apoio, informação e um senso de pertencimento e identidade social. No caso aqui estudado, a base territorial é fator fundamental na conformação dessa identidade. 
cidade do Rio de Janeiro a partir de 1994 e concluído em dezembro de 2000. Os programas partem da premissa da "territorialização" das ações em maior ou menor grau para a elaboração de políticas públicas destinadas à habitação como "tecnologias” de intervenção específica das cidades.

\section{As consequências da periferização da cidade: o caso do Rio de Janeiro}

A ocupação dos espaços da cidade em expansão iniciou-se mediante o processo de "periferização", tendo como atores os membros das classes economicamente desfavorecidas que utilizavam como recursos a autoconstrução em áreas como assentamentos irregulares ou até mesmo em loteamentos, adotando ainda como modalidade a pequena produção imobiliária, ocupando vilas e avenidas naquelas regiões recém-incorporadas. Os assentamentos irregulares são consequências da ocupação irregular, que se dá em espaços que ninguém quer pela dificuldade de construção ou pela ilegalidade. Nesse sentido, considera Porto-Gonçalves ${ }^{18}$, ao definir os conceitos de territórios a partir das relações sociais e de poder, que para os conformar é necessário analisar as territorialidades.

[...] mas ressalta a necessidade de se identificarem os sujeitos e processos que os compõem, isto é, as territorialidades. Estas territorialidades, circunscritas em territórios definidos ou não, estão em tensão, que denomina "tensões de territorialidades", as quais gestam uma nova geografia e novas cartografias. Estas tensões se dão entre os mais diversos interesses sociais, sejam eles empresariais, comunitários ou governamentais.

A reurbanização do centro do Rio de Janeiro, após a década de 20, impulsionou a expansão dos estoques residenciais das áreas em via de produção, mesclando a ocupação dos subúrbios com aquela população vinda dos cortiços e outra parte que adquiriu seus imóveis dos incorporadores que viram na região suburbana uma

${ }^{18}$ PORTO-GONÇALVES apud CAZELLA, Ademir A.; BONNAL, Philippe; MALUF, Renato S. (Org.). Agricultura familiar: multifuncionalidade e desenvolvimento territorial no Brasil. Rio de Janeiro: Mauad X, 2009. p. 29. 
grande oportunidade de ampliarem seus investimentos. A tendência à concentração e à centralização do capital nas cidades integra o processo de acumulação que, desenvolvido em crescentes escalas, criam monopólios que assumem o papel decisório na vida econômica e social das cidades. Assim, observa Lenin ${ }^{19}$ :

Se o capitalismo fizer essas coisas não seria capitalismo, pois tanto o desenvolvimento desigual como o nível de semiinanição das massas são condições essenciais e inevitáveis, e constituem as premissas desse modo de produção. Enquanto o capitalismo continuar sendo o que é, o capital excedente não será usado para elevar o padrão de vida das massas num determinado país, pois isso significaria uma redução nos lucros capitalistas, mas será usado com a finalidade de obtenção de lucros crescentes por meio da exportação de capitais a países atrasados. Nos países atrasados, os lucros são habitualmente elevados, pois o capital é escasso, o preço da terra é relativamente baixo, os salários são baixos, as matérias-primas são baratas.

A tolerância com a expansão das favelas pelos órgãos da administração pública estava relacionada à acumulação de capital concentrado nas mãos dos setores da indústria e do comércio que impunham uma dinâmica no mercado facilitada pelos baixos investimentos no material humano, sem ser necessária a qualificação desses operários. "As cidades acumulam valores de uso", que tendem à produção de valores de troca, resultando rupturas que "[...] dependem, no entanto, da forma da sociedade preexistente e da extensão da penetração capitalista"20.

A ocupação de áreas próximas ao mercado de trabalho por parte dos trabalhadores assegurava o crescimento da economia, facilitando o desenvolvimento da cidade $^{21}$. Logo, a expansão industrial do país criou uma lógica de acumulação de capital "[...] que determina a forma de produção e transformação do espaço

${ }^{19}$ LENIN apud HARVEY, David. A produção capitalista do espaço. Tradução de Carlos Szlak. São Paulo: Annablume, 2005. p. 69.

${ }^{20}$ HARVEY, David. A produção capitalista do espaço. Tradução de Carlos Szlak. São Paulo: Annablume, 2005. p. 58-59.

${ }^{21} \mathrm{O}$ fato descrito é também percebido em outros municípios da metrópole do Rio de Janeiro, como por exemplo, a cidade de Niterói. 
construído"22 , tolerando a presença de parte dos trabalhadores pobres em determinadas áreas, possibilitando o assentamento dessas novas categorias nas periferias.

A partir desse novo padrão observado, não houve alteração da política de alocação de investimentos públicos, em vigor nos anos vinte, que privilegiava as regiões centrais da cidade. Desse modo, o desenvolvimento do capitalismo em nosso país produziu novos segmentos sociais médios com diferentes padrões de consumo, marcados por uma classe trabalhadora urbana de baixa qualificação e precárias condições de reprodução $0^{23}$. Confirma essa situação Campanário ${ }^{24}$ :

Politicamente, esta situação não se tem traduzido em poder de apropriação, por parte das classes populares, das condições gerais de reprodução, isto é, os equipamentos coletivos e seus "efeitos úteis". Assim, a reprodução passa também por mecanismos "informais" caracterizados pela autoconstrução, favelamento e outras formas de reprodução doméstica de valores de uso.

Atualmente, os assentamentos precários não se colocam mais como exceção em nossas cidades, dado o enorme percentual ${ }^{25}$ de moradias precárias que não atendem a um padrão mínimo de habitabilidade, comprometendo tanto a qualidade de vida dos que ali vivem como também a qualidade urbana e ambiental do conjunto das grandes cidades. Acentuando esse quadro $\mathrm{Hegel}^{26}$ analisa:

${ }^{22}$ COUTINHO, Ronaldo. A mitologia da cidade sustentável no capitalismo. In: COUTINHO, Ronaldo; BONIZZATO, Luigi (Org.). Direito da Cidade: novas concepções sobre as relações jurídicas no espaço social urbano. Rio de Janeiro: Lúmen Juris, 2007. p. 23.

${ }^{23}$ Embora esse fenômeno aluda o período próximo à abolição da escravatura, inclusive constando de registros histórico e literário, durante décadas o poder público não enfrentou essa questão por meio de políticas públicas que garantissem o direito à moradia às famílias em áreas qualificadas como favelas e outros tipos de assentamentos precários. Somente a partir da década de 1980 que se destacam algumas experiências de programas e iniciativas de urbanização de favelas.

${ }^{24}$ CAMPANÁRIO, Milton de Abreu. O mercado de terras e a exclusão social na cidade de São Paulo. In: KRISCHKE, Paulo J. (Org.). Terra de habitação versus terra de espoliação. São Paulo: Cortez, 1984. p. 14.

${ }^{25}$ No Censo 2000, o instituto estimou em 1,6 milhão o número de domicílios em condição precária no Brasil. No Censo de 2010, o instituto verificou que 2.435.872 de pessoas residem em área não urbanizada. Disponível em: <http://www.ibge.gov.br/home/estatistica/ populacao/censo2010/sinopse_tab_brasil_pdf.shtm>. Acesso em 13 jul. 2011.

${ }^{26}$ HEGEL apud HARVEY, David. A produção capitalista do espaço. Tradução de Carlos Szlak. São Paulo: Annablume, 2005. p. 100. 
A pobreza em si não transforma os homens em ralé [...] Contra a natureza, o homem não pode reivindicar direito algum, mas quando se estabelece a sociedade, a pobreza imediatamente assume a forma de uma má ação de uma classe contra outra. A importante questão de como a pobreza será abolida é uma das questões mais perturbadoras que inquietam a sociedade moderna.

Diante desse cenário social, apresentou-se um processo de industrialização que, no Brasil, chegou ao seu ponto culminante através da intensificação da atividade econômica nos períodos compreendidos entre anos de 1940 a 1970, acarretando a expansão da ocupação de determinadas áreas da cidade ${ }^{27}$.

[...] Duas gerações urbanísticas depois, o que poderia ter sido motivo de escândalo - a revelação da mercadorização integral de um valor de uso civilizatório como a cidade tornou-se razão legitimadora ostensivamente invocada: aqui a novidade realmente espantosa, e tanto mais que eficiente, não só por deixar a crítica espontânea da cidadeempresa com a sensação de estar arrombando uma porta aberta, mas, sobretudo por contar com a 'compreensão' das populações deprimidas por duas décadas de estagnação econômica e catástrofe urbana: fica assim bem mais simples persuadi-las a se tornarem 'competitivas', na pessoa de suas camadas 'dinâmicas', bem entendidas. Esse o núcleo originário da 'sensação coletiva de crise', sublimada pela nova ênfase na auto-imagem dos habitantes, tal como lhes é devolvida pela superfície refletora dos Grandes Projetos, neste final de século.

Tal fato caracterizou durante essas décadas o quadro de miséria e pobreza existente até os dias atuais no Rio de Janeiro ${ }^{28}$. O quadro urbano, a partir dos anos setenta, é marcado pela aplicação de políticas que privilegiavam a lógica ditada pelos interesses dos grupos de empreendedores ${ }^{29}$, consagrando como meta a acumulação de patrimônio e traçando uma nova dinâmica de ocupação. Conforme

${ }^{27}$ ARANTES, Otília Beatriz Fiori. Uma estratégia fatal: a cultura nas novas gestões urbanas. Petrópolis: Vozes, 2000. p. 17.

${ }^{28}$ PIQUET, Rosélia et. al. O desenvolvimento urbano em questão. 2. ed. Rio de Janeiro: IPPUR, 2001.

${ }^{29}$ PÓLIS, Nelson Saule Júnior et al. (Org.) Assentamentos urbanos: Brasil século XXI - os caminhos da sustentabilidade cinco anos depois da Rio 92. Rio de Janeiro: FASE, 1997. 
acentua Milton Santos ${ }^{30}$, a cidade e a urbanização corporativas são resultado de um esforço realizado pelo próprio poder público que se funda na lógica dominante dos privilégios e especulação, provocando a produção de espaços vazios.

O próprio poder público torna-se criador privilegiado de escassez; estimula, assim, a especulação e fomenta a produção de espaços vazios dentro das cidades; incapaz de resolver o problema da habitação, empurra a maioria da população para as periferias; e empobrece ainda mais os mais pobres, forçados a pagar caro pelos precários transportes coletivos e a comprar caro bens de um consumo indispensável e serviços essenciais que o poder público não é capaz de oferecer.

O resultado foi o agravamento do cenário urbano e a composição do perfil dual onde os ricos ocupam as áreas nobres da cidade ${ }^{31}$ e os investimentos públicos em infraestrutura e serviços básicos estão presentes, deixando as áreas remanescentes para o uso da população menos favorecida ${ }^{32}$.

Como parte da regra do jogo, a ocupação de terras urbanas tem sido tolerada. O Estado não tem exercido, como manda a lei, o poder de polícia. A realidade urbana é prova insofismável disso. Impossível admitir o contrário, pois se essa gigantesca ocupação de terras não fosse tolerada e a população pobre ficasse sem alternativa nenhuma, teríamos uma situação de guerra civil, considerando os números envolvidos. Para dar uma ordem de grandeza, estamos nos referindo a aproximadamente dois milhões de pessoas que moram em favelas, apenas no município de São Paulo. Não é em qualquer localização, entretanto, que a invasão de terras urbanas é tolerada. Nas áreas valorizadas pelo mercado, a lei se aplica.

${ }^{30}$ SANTOS, Milton. A natureza do espaço. Técnica e tempo. Razão e emoção. São Paulo: EDUSP, 2002. p. 123.

${ }^{31}$ ABRAMO, Pedro. Cidades em transformação: entre o plano e o mercado - experiências internacionais em gestão do solo urbano. Rio de Janeiro: Observatório Imobiliário de Políticas do Solo, 2001. p. 285. Considera o festejado autor que: "O valor da terra/propriedade urbana é determinado pelo mercado formal em razão de diversos fatores tais como o processo de especulação imobiliária, localização física e territorial, potencial de uso e de construção, oferta de serviços e equipamentos públicos, potencial de uso da infra-estrutura urbana, capacidade da rede viária, oferta e qualidade do transporte".

${ }^{32}$ MARICATO, Ermínia. Metrópole na periferia do capitalismo: desigualdade, ilegalidade e violência. São Paulo: Hucitec, 1996. p. 160. 
Diariamente os trabalhadores passaram a desenvolver suas novas tarefas e também a adquirir produtos e serviços fora dos seus municípios de origem, transformados em verdadeiras "cidades dormitórios"33, sem um setor de comércio ou serviço pujante. A realidade demonstra uma ocupação seletiva das cidades periféricas da metrópole por estabelecimentos, principalmente nas atividades de alimentação e alojamento, desse modo estabelecendo um processo de urbanização crescente nas áreas limítrofes ao grande centro. Otília Arantes ${ }^{34}$ afirma que:

[...] embora se saiba que as cidades modernas sempre estiveram associadas à divisão social do trabalho e à acumulação capitalista, que a exploração da propriedade do solo não seja um fato novo, e que haja - como mostrou à exaustão Lefèbvre e depois toda a geografia humana recente - uma relação direta entre a configuração espacial urbana e a produção ou reprodução do capital, como estamos vendo, há algo de novo a registrar nessa fase do capitalismo em que as cidades passaram mesmas a ser geridas e consumidas como mercadorias.

O processo econômico no estado do Rio de Janeiro, no período dos anos setenta, baseou-se em especial na produção de moradias. O setor da construção civil obteve um crescimento a partir da década de sessenta em grande parte atribuído à política desenvolvida pelo SFH (Sistema Financeiro de Habitação). Desde então, circularam somas consideráveis de capital financeiro que geraram somas consideráveis de recursos para o insipiente mercado imobiliário ${ }^{35}$.

A contradição está no "valor de uso que o lugar representa para seus habitantes e o valor da troca com que ele se apresenta para aqueles interessados em

${ }^{33}$ LAGO, Luciana Corrêa do. Desigualdades e segregação na metrópole: o Rio de Janeiro em tempo de crise. Rio de Janeiro: Revan, 2000.

${ }^{34}$ ARANTES, Otília Beatriz Fiori et al. Urbanismo em fim de linha e outros estudos sobre o colapso da modernização arquitetônica. São Paulo: EDUSP, 1998. p. 26.

${ }^{35}$ CARDOSO, Adauto Lúcio; RIBEIRO, Luiz Cesar de Queiroz (Coord.). A municipalização das políticas habitacionais: uma avaliação da experiência recente: 1993 -1996. Rio de Janeiro: UFRJ/IPPUR, 2006. 
extrair dele um benefício econômico qualquer, [...]"36. Dessa forma, geraram-se rentáveis alternativas para o capital ser remunerado de maneira atrativa.

Importantes ingressos de recursos do setor financeiro para a área destinada a atender a demanda represada por moradia pelos assalariados ocorreram após os anos setenta. Essa tarefa foi desenvolvida pela atuação de grandes oligopólios de incorporadoras que, somadas às participações das pequenas e médias empresas responsáveis pela construção dos chamados conjuntos habitacionais, repartiam o cenário com empreiteiros individuais. O modelo do Sistema Financeiro de Habitação, utilizando os recursos do FGTS (Fundo de Garantia por Tempo de Serviço), implementado a partir de 1965, baseava-se no retorno do investimento para gerar novos financiamentos. Nesse sentido, observa Ermínia Maricato ${ }^{37}$ :

O SFH possibilitou a capitalização das empresas ligadas à provisão de Habitações, permitiu a estruturação de uma rede de agentes financeiros privados, permitiu a realização do financiamento à produção e também o financiamento do consumo. O longo tempo do giro do capital na produção e o longo tempo de circulação da mercadoria habitação foram aliviados por meio da entrada desses recursos. A política de concentração de renda levada a efeito durante o período assinalado (1968-1980) viabilizou a ampliação de um mercado imobiliário para a provisão de residências do tipo capitalista.

Em 1980, foi possível constatar que os recursos não contemplavam um contingente de aproximadamente trezentas mil famílias, com rendimentos inferiores a dois salários mínimos. Os excluídos do crédito do SFH (Sistema Financeiro de Habitação) utilizavam-se da autoconstrução, inclusive na modalidade cooperada, conhecida por mutirão. O setor imobiliário foi incentivado a expandir sua atuação para outras áreas da capital por meio de investimentos, na sua infraestrutura, realizados com verbas públicas.

\footnotetext{
${ }^{36}$ ARANTES, Otília Beatriz Fiori et al. Urbanismo em fim de linha e outros estudos sobre o colapso da modernização arquitetônica. São Paulo: EDUSP, 1998. p. 26.

${ }^{37}$ MARICATO, Ermínia. Metrópole na periferia do capitalismo: desigualdade, ilegalidade e violência. São Paulo: Hucitec, 1996. p. 30.
} 
As parcerias firmadas entre o capital privado e o poder público retratam a abordagem empreendedora do governo local resultante da mudança de paradigma na era da governança urbana, desempenhando um papel chave no desenvolvimento capitalista no "regime de acumulação flexível" na década de oitenta, como relata David Blunkett ${ }^{38}$ :

No início da década de 1970, depois que a política do pleno emprego deixou de ser uma das principais prioridades governamentais, os conselhos locais passaram a assumir esse desafio, apoiando as pequenas empresas, criando vínculos mais estreitos entre os setores público e privado, e promovendo áreas locais para atração de novos empreendimentos. Começaram a adaptar o tradicional papel econômico do governo local britânico, que oferecia incentivos sob a forma de subvenções, empréstimos a fundo perdido e infraestrutura subsidiada, e não exigia envolvimento recíproco com a comunidade, para atrair empresas industriais e comerciais que procuravam locais adequados para investimento e comércio [...]. Atualmente, como no passado, o governo local é capaz de imprimir sua própria marca empreendedora e empresarial, enfrentando a grande mudança econômica e social provocada pela reestruturação tecnológica e industrial.

Outro elemento favorável para o êxito da autoconstrução foi a tentativa frustrada das autoridades públicas de impedir o processo de favelização, o qual teve seu início no século passado, na década de setenta. Houve um redimensionamento desses assentamentos para outras áreas onde a prática foi tolerada, gerando o crescimento daquela população nos subúrbios cariocas e no interior fluminense. O derradeiro fator de incremento da autoconstrução foi a remoção das populações faveladas da Zona Sul da cidade para as novas áreas ${ }^{39}$ :

Essa transição será, pois, traduzida em um movimento de deslocamento espacial das famílias, cujo resultado é a reconfiguração da hierarquia sócio-espacial das localidades urbanas. Vê-se, então, que o principal fator de convergência

38 BLUNKETT, David apud HARVEY, David. A produção capitalista do espaço. Tradução de Carlos Szlak. São Paulo: Annablume, 2005. p. 167.

39 ABRAMO, Pedro. Cidades em transformação: entre o plano e o mercado - experiências internacionais em gestão do solo urbano. Rio de Janeiro: Observatório Imobiliário de Políticas do Solo, 2001. p. 173. 
das antecipações especulares que darão nascimento a esta convenção urbana é a proposição de uma inovação espacial e que o deslocamento ocasionado bem revela o fato de uma localização ter sido depreciada de maneira 'fictícia'.

É possível verificar que a ocupação demográfica espacial consolidou-se mediante uma estrutura sócio-espacial marcada pela desigualdade nas formas de produção do espaço metropolitano, acentuando um mercado imobiliário na década de setenta, com demasiada oferta de apartamentos para a classe média nas áreas nobres da cidade, gerando, como contrapartida, a favelização dos subúrbios e nas encostas de morros e a crescente oferta de lotes populares na periferia.

A depreciação residencial gerou a mobilidade na ocupação do espaço físico urbano e o fluxo de moradores dessas áreas para outras disponíveis, proporcionando uma destruição da criativa externalidade representada pelas relações oriundas das interações decorrentes da vizinhança. Portanto, aquela proposição de uma convenção urbana possuiu como efeito colateral a modificação das relações de vizinhança de certa localidade onde se estrutura uma nova dinâmica residencial urbana caracterizada pela constante apropriação de áreas anteriormente desvalorizadas e agora valorizadas, levando os antigos ocupantes a uma permanente condição de nômades urbanos.

\section{Algumas intervenções realizadas nas comunidades do Rio de Janeiro pelo PAC}

Dentre as obras de grande porte envolvendo eliminação de risco e deficiências de infraestrutura urbana se destacam aquelas realizadas no Complexo do Alemão, na cidade do Rio de Janeiro/RJ, que até o presente momento obteve um investimento de R\$ 833,2 milhões, com fonte do Orçamento Geral da União, recursos obtidos por meio do financiamento pelo FGTS e FAT e apresentando como entes proponentes o governo do Estado do Rio de Janeiro e o Município do Rio de Janeiro. Foram beneficiadas em torno de 30.266 famílias.

As principais intervenções foram a produção de 920 unidades habitacionais, aquisição de 1.155 unidades habitacionais, obras de infraestrutura compre- 
endendo abastecimento de água, esgotamento sanitário, rede de energia elétrica, iluminação pública, pavimentação, obras viárias e drenagem pluvial, além de recuperação de áreas degradadas, proteção, contenção e estabilização de solo, instalação de recipientes para coleta de resíduos sólidos, construção de teleférico com sete estações. Também foram instalados equipamentos comunitários, tais como o centro de referência da juventude, centro de geração de renda, a escola de ensino médio de referência, biblioteca, centro de integração de atenção à saúde, centro de serviços, duas creches, dois centros comerciais e dois postos de saúde da família.

Outra importante intervenção do PAC no estado do Rio de Janeiro foi a realizada na comunidade da Rocinha, na cidade do Rio de Janeiro que contou com a ordem de $\mathrm{R} \$ 231,2$ milhões em investimentos com fonte de recursos extraídos do Orçamento Geral da União, apresentando como proponente o governo do Estado do Rio de Janeiro. Estima-se que foram beneficiadas, direta e indiretamente, aproximadamente 30.000 mil famílias com os seguintes serviços:

a) Produção de 144 unidades habitacionais;

b) aquisição de 603 unidades habitacionais;

c) melhoria de 2.661 unidades habitacionais;

d) infraestrutura compreendendo abastecimento de água, esgotamento sanitário, drenagem pluvial, iluminação pública, pavimentação e obras viárias;

e) proteção, contenção e estabilização de encostas;

f) recuperação de áreas degradadas;

g) construção do Plano Inclinado I, com 03 estações, e do Plano Inclinado II, com 02 estações; e

h) equipamentos comunitários como creche, centro de integração, centro integrado de atenção à saúde - CIAS, centro de convivência, cultura e cidadania - C4, centro de judô e mercado público.

Por fim, destaca-se a intervenção realizada no Morro do Preventório, na cidade de Niterói, tendo como ente proponente do conjunto de ações o governo do estado do Rio de Janeiro, com parceria do governo federal e da prefeitura municipal. Os recursos para a realização das intervenções urbanísticas foram retirados do Orçamento Geral da União (OGU). 
A intervenção beneficiou cerca de mil setecentos e setenta e duas famílias residentes na área do Preventório. Conforme esclarecido, o assentamento localizava-se em uma APP e apresentava uma configuração topográfica em aclive, bastante acidentada, com grande risco de deslizamentos das encostas.

O projeto previu a construção de duzentas e quarenta e oito unidades habitacionais, distribuídas em quatro blocos de apartamentos com dois pavimentos, além da implantação de equipamentos comunitários, sistema de coleta de águas pluviais, obras viárias e recuperação de áreas degradadas, por meio das atividades da equipe social, que organizou ações comunitárias de educação sanitária e ambiental e programas de geração de trabalho e renda.

A situação fundiária foi regularizada com a titulação definitiva dos lotes aos moradores através da usucapião especial urbana e a concessão real de uso para fins de moradia.

\section{A questão fundiária e as intervenções do PAC}

Durante a execução dos projetos do PAC, verificou-se que a questão fundiária acarretou duas intervenções estatais em momentos distintos.

Inicialmente, foram identificados os títulos de propriedade e, através dos Cartórios de Registro de Imóveis (CRI), comprovada a dominialidade como garantia da regularização patrimonial dos interessados. Averiguou-se que grande parcela dessas áreas escolhidas pertencia ao poder público e outra parcela menor aos particulares.

Após a identificação do domínio, passou-se a adotar as seguintes medidas, em razão do interesse público ou social: (a) áreas cujo processo de desapropriação encabeçado por entes públicos ainda se encontrasse com registro da titularidade do imóvel em trâmite; (b) áreas devolutas; (c) áreas recebidas em doação por entes públicos, pessoas físicas ou jurídicas, nesse caso, com apresentação de promessa formal de doação irretratável e irrevogável; (d) áreas que, independentemente da 
sua dominialidade, estejam inseridas em Zona Especial de Interesse Social (ZEIS); (e) áreas objeto de sentença favorável aos ocupantes, transitada em julgado, proferida em ação judicial de usucapião ou concessão de uso especial para fins de moradia.

Num segundo momento, apuraram-se quais seriam os instrumentos legais previstos pelo Estatuto da Cidade e outras legislações para regularizar a posse dos beneficiários. O principal objetivo desse processo foi a constituição do direito real sobre o imóvel para as famílias beneficiadas. Para tanto, foram adotados os seguintes instrumentos de regularização fundiária: (a) cessão de uso; (b) concessão de direito real de uso; (c) concessão de uso especial para fins de moradia; (d) usucapião especial urbano; (e) aforamento; (f) direito de superfície; (g) doação; (h) alienação; e (i) legitimação da posse.

Destaca-se que a legitimação da posse foi um instrumento inserido pelo advento da Lei Federal n. 11.977/2009, que regula o programa "Minha Casa, Minha Vida” e dá outras providências. Dentre os dispositivos legais, merece alusão o art. 49 da citada lei, que prevê a possibilidade do município dispor sobre o procedimento de regularização fundiária em seu território.

Outro dispositivo importante da Lei Federal n. 11.977/2009 é o art. 51, que apresenta os requisitos mínimos para o processo de regularização fundiária de iniciativa do ente local, sendo eles, a identificação dos lotes a serem regularizados e moradias a serem realocadas, a demarcação das vias de circulação e demais áreas públicas, a adoção de medidas para promover a sustentabilidade urbanística, social e ambiental, a elaboração de um plano para determinar as reais condições para promover a segurança da população em risco e, por fim, a adequação da infraestrutura urbana.

A legitimação da posse prevista pelo diploma retrocitado, em seu art. 47, inciso VII, permite ainda a regularização fundiária de interesse social, compreendendo assentamentos ocupados predominantemente por população de baixa renda, nos casos em que estejam preenchidos os requisitos para usucapião especial urbano ou concessão de uso especial para fins de moradia; de imóveis situados em 
ZEIS ou de áreas públicas declaradas de interesse para implantação de projetos de regularização fundiária de interesse social.

$\mathrm{O}$ art. 54 da lei referida dispõe sobre a regularização fundiária de interesse específico, compreendendo os casos não enquadrados nos termos acima, e prescreve os parâmetros urbanísticos e ambientais específicos para o assentamento e a regularização das ocupações em Áreas de Preservação Permanente (APP's) ocupadas até 31 de dezembro de 2007 e inseridas em área urbana consolidada, vinculada à comprovação em estudo técnico realizado por profissionais que integrariam a equipe multidisciplinar, promovendo a intervenção para a melhoria das condições ambientais existentes nos assentamentos precários.

A regularização urbanística foi condição para o registro da área do assentamento no Cartório de Registro de Imóveis. A regularização urbanística poderá exigir a inclusão do assentamento em ZEIS, por lei municipal, sendo fundamental para a plena integração da área à cidade e para a manutenção, por parte do município, das obras de urbanização implantadas.

A regularização fundiária dos assentamentos ilegais e irregulares necessitou de uma organizada articulação promovendo o trabalho social, com o ritmo das obras de engenharia e com os órgãos licenciadores envolvidos, por meio de um plano específico contendo um cronograma físico de todas as atividades jurídicas e administrativas necessárias.

Foram etapas para a regularização fundiária de diversos assentamentos beneficiados pelo PAC as seguintes: (a) a identificação da situação fundiária, por meio de pesquisa junto ao Cartório de Registro de Imóveis, ao Judiciário e demais entidades públicas; (b) elaboração ou atualização de levantamento topográfico, preferencialmente georreferenciado, bem como compra de fotos aéreas ou imagens de satélite, desde que não disponíveis no banco de imagens do Ministério das Cidades para doação; (c) elaboração de projetos voltados à regularização fundiária, envolvendo plantas, memorial descritivo da poligonal do assentamento e cadastro físico de lotes e domicílios; (d) atividades de mobilização comunitária voltadas à regularização fundiária; (e) elaboração de cadastro socioeconômico dos beneficiá- 
rios contendo as informações necessárias à instrução dos processos de regularização fundiária; (f) coleta de documentos pessoais dos moradores, necessários à instrução dos processos de regularização fundiária; e (g) medidas administrativas e legais necessárias para a aplicação dos instrumentos de regularização fundiária tais como desafetação, criação e regulamentação de ZEIS, regulamentação de outros instrumentos de regularização e elaboração de títulos de posse ou de propriedade.

\section{Considerações finais}

Durante décadas a política habitacional praticada era de remoção e desestímulo à favela, como resposta ao processo de controle dos assentamentos localizados em áreas nobres, o que acentuou o processo de segmentação social do espaço urbanístico.

Com a vigência do Estatuto da Cidade, que constitui um marco histórico para a política urbana uma vez que estabeleceu importantes instrumentos de intervenção na cidade e definiu mecanismos mais adequados ao atendimento das necessidades da parcela da população que ocupa o espaço informal da cidade, pode-se dizer que houve um acentuado índice de modernização na dinâmica de ocupação do solo urbano constituindo um avanço para o processo de democratização das cidades.

Os governos locais enfrentam diversas crises ao tentarem controlar e orientar o uso, o desenvolvimento e a expansão das cidades. Esse problema é agravado pelo fato de o crescimento e o desenvolvimento das cidades serem deixados ao encargo dos mercados imobiliários formal e informal que visam, principalmente, à especulação nas áreas nobres para atenderem diretamente os seus interesses, maximizando os lucros e tornando o empreendimento rentável.

Para combater esse quadro, o Estatuto da Cidade constitui um marco histórico para a política urbana, pois estabelece instrumentos de intervenção na cidade, adotando mecanismos mais adequados ao atendimento das necessidades da parcela da população que ocupa o espaço informal da cidade. 
O Estatuto da Cidade possui instrumentos que visam à efetividade da regularização fundiária dos assentamentos considerados irregulares ou clandestinos. O objetivo final é a democratização do acesso à moradia formal e ao solo urbano.

Com a criação do Ministério das Cidades em 2003 e a fixação de uma política habitacional a partir de 2007 por meio do Programa de Aceleração do Crescimento - PAC da habitação percebe-se que medidas como a urbanização de assentamentos ilegais e informais, o saneamento ambiental e a regularização fundiária já foram implementadas, mas ainda não contemplam a maioria dos assentados nesses espaços.

Os projetos de urbanização de assentamentos precários inseridos no PAC contemplaram ações, obras e serviços visando proporcionar a superação das condições de precariedade dos assentamentos escolhidos, incorporando-os à cidade formal, com abordagem das questões urbana, habitacional, fundiária, social e ambiental.

Concluí-se que, para evitar a formação de novas ilegalidades, como locação ou venda das moradias concedidas, deve-se pensar em um conjunto de medidas econômicas, tributárias e tarifárias para subsidiar os novos custos transferidos para os moradores. E que agora se vêem obrigados a aumentar a renda familiar ou transformar essa nova moradia em um ativo econômico a ser vendido para uma nova família com maior renda capaz de pagar os tributos e encargos, até então não pagos, e mudar para outra moradia precária.

\section{Public housing policy and growth acceleration program: Rio de Janeiro's state interventions analysis}

\section{Abstract}

This paper's objective is to examine public housing policies implemented by the Growth Acceleration Program (PAC) and the interventions of urbanization in slums and shanty towns in the Rio de Janeiro state. In the first part it will be 
examined the land question after the promulgation of the 1988 Constitution and the Statute of the City, as well as the inclusion of the issue of land regularization in Land Affairs Forum created by the Justice National Council. It is also discussed the territorialization of housing policy investment implemented by the housing PAC promoting the social inclusion process developed by the federal government to implement its national policy of slum upgrading promoting, along with other measures, land regularization with the states and government cooperation through municipal sources obtained by the agents involved in the research. Finally, it will study the major historical interventions conducted in the metropolitan region of Rio de Janeiro and comparing them with the actions already implemented by PAC, reflecting on the instruments used in PAC regularization to ensure the right to decent housing in communities. It is concluded that through improvements projects of precarious settlements inserted into the PAC were contemplated actions, works and services aiming to overcome the precariousness of the settlements chosen to incorporate them into the formal city, with the approach of urban, housing, land, social and environmental issues. However, to avoid the formation of new illegalities, it should be considered a set of economic measures, tax and fare to subsidize the costs transferred to the attended new residents.

Keywords: Growth Acceleration Program. Regularization. City Statute. Public Housing Policy.

\section{Referências}

ABRAMO, Pedro. Cidades em transformação: entre o plano e o mercado experiências internacionais em gestão do solo urbano. Rio de Janeiro: Observatório Imobiliário de Políticas do Solo, 2001.

ACSELRAD, Henri. A duração das cidades: sustentabilidade e risco nas políticas urbanas. 2. ed. Rio de Janeiro: Lamparina, 2009.

ALFONSIN, Betânia de M. Instrumentos e experiências da regularização fundiária em áreas urbanas. Questões urbanas: espaço global e regional; interiorização, São Paulo, v. 9, n. 3, p. 05-26, jul./set. 1995. 
ALFONSIN, Betânia de M. Políticas de regularização fundiária: justificação, impactos e sustentabilidade. In: FERNANDES, Edésio (Org.). Direito urbanístico e política urbana no Brasil. Belo Horizonte: Del Rey, 2001. p. 195-267.

ALFONSIN, Betânia de M. Da invisibilidade à regularização fundiária: a trajetória legal da moradia de baixa renda em Porto Alegre. In: FERNANDES, Edésio; ALFONSIN, Betânia de M. (Org.). A lei e a ilegalidade na produção do espaço urbano. Belo Horizonte: Del Rey; Lincoln Institute, 2003. p. 157-172.

ALFONSIN, Betânia de M. Para além da regularização fundiária: Porto Alegre e o urbanizador social. In: ALFONSIN, Betânia de M.; FERNANDES, Edésio (Org.). Direito à moradia e segurança da posse no Estatuto da Cidade: diretrizes, instrumentos e processos de gestão. Belo Horizonte: Fórum, 2004. p. 298-368.

ARANTES, Otília Beatriz Fiori. Uma estratégia fatal: a cultura nas novas gestões urbanas. Petrópolis: Vozes, 2000.

ARANTES, Otília Beatriz Fiori et al. Urbanismo em fim de linha e outros estudos sobre o colapso da modernização arquitetônica. São Paulo: EDUSP, 1998.

BECKER, Bertha Koiffmann. Novas territorialidades na Amazônia: desafio às políticas públicas. Boletim do Museu Paraense Emilio Goeldi: ciências humanas. Belém, v. 5, n. 1, p. 17-23, jan./abr. 2010. Disponível em: <www.museu-goeldi.br/ editora/bh/artigos/.../dossie_novas(becker).pdf>. Acesso em: 23 fev. 2011.

BOLAFFI, G. Para uma nova política habitacional e urbana: possibilidades econômicas alternativas operacionais e limites políticos. In: VALLADARES, Lícia (Org.). Habitação em questão. Rio de Janeiro: Zahar, 1979.

BRASIL. Constituição da República Federativa do Brasil de 1988. Disponível em: <http://www.planalto.gov.br/ccivil_03/constituicao/constitui\%C3\%A7ao.htm>. Acesso em: 20 out. 2010.

BRASIL. Lei n. 10.257, de 10 de julho de 2001. Regulamenta os arts. 182 e 183 da Constituição Federal. Estabelece diretrizes gerais da política urbana e dá outras providências. Disponível em: <http://www.planalto.gov.br/ccivil_03/Leis/ LEIS_2001/L10257.htm>. Acesso em: 20 out. 2010.

BRASIL. Lei n. 11.977, de 7 de julho de 2009. Dispõe sobre o Programa Minha Casa, Minha Vida - PMCMV e a regularização fundiária de assentamentos localizados em áreas urbanas; altera o Decreto-Lei no 3.365, de 21 de junho de 1941, as Leis nos 4.380, de 21 de agosto de 1964, 6.015, de 31 de dezembro de 1973, 8.036, de 11 
de maio de 1990, e 10.257, de 10 de julho de 2001, e a Medida Provisória no 2.19743, de 24 de agosto de 2001; e dá outras providências. Disponível em: <http://www. planalto.gov.br/ccivil_03/_ato2007-2010/2009/lei/111977.htm>. Acesso em: 26 out. 2010.

BRASIL. Lei n. 10.406, de 10 de janeiro de 2002. Institui o Código Civil. Disponível em: <http://www.planalto.gov.br/ccivil/leis/2002/L10406.htm>. Acesso em: 26 out. 2010 .

BRASIL. Ministério das Cidades. Secretaria Nacional de Habitação. Urbanização de Favelas: a experiência do PAC. Brasília, 2010. Disponível em: <wuf5.cidades. gov.br/.../Ministério_lança_Estatuto_da_Cidade_Comentadono_FUM5.aspx >. Acesso em: 12 out. 2010.

BRASIL. Ministério das Cidades. Painel PAC: habitação e saneamento ambiental. Disponível em: <www.cidades.gov.br/.../painel-pac-habitacao-e-saneamentoambiental>. Acesso em: 10 ago. 2010.

BRASIL. PAC - Favela: a construção social do território e a moradia como local de produção no morro do Preventório. Disponível em: <www.anpur.org.br/anais/ ena13/.../GT1-297-451-20081219190503.pdf>. Acesso em: 10 nov. 2010.

BRASIL. Resolução n. 110, 6 de abril de 2010. Institucionaliza, no âmbito do Conselho Nacional de Justiça, o Fórum de Assuntos Fundiários, de caráter nacional e permanente, destinado ao monitoramento dos assuntos pertinentes a essa matéria e à resolução de conflitos oriundos de questões fundiárias, agrárias ou urbanas. Disponível em: <http://www.cnj.jus.br/index.php?option=com_cont ent\&view=article\&id=10575:resolucao-no-110-de-06-de-abril-de-2010\&catid=57 :resolucoes\&Itemid=512>. Acesso em: 12 jan. 2011.

BRASIL. Superior Tribunal de Justiça. 2a. Turma, REsp 324.417, 2001. Disponível em: <http://www.stj.jus.br/webstj/Processo/Justica/detalhe.asp?numreg=2001006 54658\&pv=000000000000>. Acesso em: 2 dez. 2010.

CARDOSO, Adauto Lucio. Habitação social nas metrópoles brasileiras: uma avaliação das políticas habitacionais em Belém, Recife, São Paulo, Rio de Janeiro, Belo Horizonte e Porto Alegre no final do Século XX. Rio de Janeiro: Antac, 2007.

CARDOSO, Adauto Lúcio; RIBEIRO, Luiz Cesar de Queiroz (Coord.). A municipalização das políticas habitacionais: uma avaliação da experiência recente: 1993 -1996. Rio de Janeiro: UFRJ/IPPUR, 2006. 
CAMPANÁRIO, Milton de Abreu. O mercado de terras e a exclusão social na cidade de São Paulo. In: KRISCHKE, Paulo J. (Org.). Terra de habitação versus terra de espoliação. São Paulo: Cortez, 1984. p. 11-30.

CASTELLS, Manuel. A questão urbana. Rio de Janeiro: Paz e Terra, 1983.

CAZELLA, Ademir A.; BONNAL, Philippe; MALUF, Renato S. (Org.). Agricultura familiar: multifuncionalidade e desenvolvimento territorial no Brasil. Rio de Janeiro: Mauad X, 2009.

COMPANS, R. A regularização fundiária de favelas no Estado do Rio de Janeiro. Revista de Janeiro, Rio de Janeiro, v. 1, n. 9, p. 41-53, jan./abril. 2003.

COUTINHO, Ronaldo. A mitologia da cidade sustentável no capitalismo. In: COUTINHO, Ronaldo; BONIZZATO, Luigi (Org.). Direito da Cidade: novas concepções sobre as relações jurídicas no espaço social urbano. Rio de Janeiro: Lúmen Juris, 2007. p. 17-52.

DALLARI, Adilson Abreu. Instrumentos da política urbana. In: In: DALLARI, Adilson; FERRAZ, Sérgio (Org.). Estatuto da cidade - comentários à Lei Federal 10.257/2001. São Paulo: Malheiros, 2003, p. 77-78.

DAVIDOVITCH, Fany. Urbanização brasileira: tendências, problemas e desafios. Revista de estudos regionais e urbanos, São Paulo, v. 4, n. 13, p. 12-29, ago./dez. 1984.

DAVIS, Mike. Planeta favela. São Paulo: Boitempo, 2006.

GLOBO. Programa Bom Dia Brasil. Disponível em: <http:/g1.globo.com/bomdia-brasil/noticia/2011/02/regras-do-programa-minha-casa-minha-vida-sofremnovas-alteracoes.html>. Acesso em: 28 fev. 2011.

ENGELS, F. Contribuição ao problema da habitação. In: MARX, K.; ENGELS, F. Textos. São Paulo: Edições Sociais, 1976. p. 41-95.

FERNANDES, Edésio. A regularização de favelas no Brasil: o caso de Belo Horizonte. In: FERNANDES, Edésio. (Org.). Direito urbanístico. Belo Horizonte: Del Rey, 1998. p. 138-144.

FERNANDES, Edésio. Regularização de assentamentos informais: o grande desafio dos municípios, da sociedade e dos juristas brasileiros. Revista Fórum de Direito Urbano e Ambiental, Belo Horizonte, v. 1, n. 5, p. 440-446, set./out. 2002. 
FERNANDES, Edésio. Legalização de favelas em Belo Horizonte: um novo capítulo na História? In: FERNANDES, Edésio; ALFONSIN, Betânia. A Lei e a ilegalidade na produção do espaço urbano. Belo Horizonte: Del Rey, 2003. p. 469-485.

FÓRUM NACIONAL DE REFORMA URBANA. Seminário nacional - 10 anos do estatuto da cidade: avanços e desafios da política urbana brasileira, 2011. São Paulo: Secretaria Nacional de Programas Urbanos do Ministério das Cidades; Instituto de Pesquisa em Planejamento Urbano e Regional da Universidade Federal do Rio de Janeiro; Instituto Pólis, fev. 2011. Disponível em: <http://www. forumreformaurbana.org.br/index.php/noticias/168-seminario-nacional-10anos-do-estatuto-da-cidade-avancos-e-desafios-da-politica-urbana-brasileira. html>. Acesso em: fev. 2011.

HALL, Peter. Cidades do amanhã. Tradução de Perola de Carvalho. São Paulo: Perspectiva, 2009.

HARVEY, David. A produção capitalista do espaço. Tradução de Carlos Szlak. São Paulo: Annablume, 2005.

HARVEY, David. Condição pós-modernidade. Tradução de Adail Ubirajara Sobral e Maria Stela Gonçalves. São Paulo: Loyola, 1993.

HARVEY, David. Justiça social e a cidade. Tradução de Armando Corrêa da Silva, São Paulo: Hucitec, 1980.

IGLESIAS, Sérgio; SOUZA, Nunes de. Direito à moradia e de habitação: análise comparativa e suas implicações teóricas e práticas com os direitos da personalidade. São Paulo: Revista dos Tribunais, 2004.

INSTITUTO POLIS. Carta Mundial do Direito à Cidade, 2004. Disponível em: $<$ http://www.polis.org.br/artigo_interno.asp?codigo=12>. Acesso em: 18 set. 2010.

LAGO, Luciana Corrêa do. Desigualdades e segregação na metrópole: o Rio de Janeiro em tempo de crise. Rio de Janeiro: Revan, 2000.

MAGALHÃES, Sérgio. A cidade na incerteza: ruptura e contiguidade em urbanismo. Rio de Janeiro: Viana \& Mosley Editora, 2007.

MAGALHÃES, Sérgio. Sobre a cidade: habitação e democracia no Rio de Janeiro. São Paulo: ProEditores, 2002. 
MAGALHÃES, Sérgio. Cidade Inteira: a política habitacional da cidade do Rio de Janeiro. Rio de Janeiro: Prefeitura da Cidade do Rio de Janeiro, 1999.

MARICATO, Ermínia. Habitação e as políticas fundiárias, urbana e ambiental. Brasília: PNUD; Ministério das Relações Exteriores, 1995.

MARICATO, Ermínia. Metrópole na periferia do capitalismo: desigualdade, ilegalidade e violência. São Paulo: Hucitec, 1996.

MARICATO, Ermínia. Brasil, cidades: alternativas para a crise urbana. 3. ed. Petrópolis: Vozes, 2008.

ORGANIZAÇÃO DAS NAÇÕES UNIDAS. Declaração dos direitos humanos. Brasília, 2004. Disponível em: <http://www.onu-brasil.org.br/documentos_ direitoshumanos.php>. Acesso em: 13 jan. 2011.

OSORIO, Letícia Marques et al. Estatuto da cidade e reforma urbana: novas perspectivas para as cidades brasileiras. Porto Alegre: S. A. Fabris, 2002.

PEREIRA, Luís Portella. A função social da propriedade urbana. Porto Alegre: Síntese, 2003.

PIQUET, Rosélia et. al. O desenvolvimento urbano em questão. 2. ed. Rio de Janeiro: IPPUR, 2001.

PRETECEILLE, Edmond; VALLADARES, Licia. O futuro das metrópoles: desigualdades e governabilidade. Rio de Janeiro: Revan-Fase, 2000.

RIBEIRO, Luiz Cesar de Queiroz et al. Globalização, fragmentação e reforma urbana: o futuro das cidades brasileiras na crise. Rio de Janeiro: Civilização Brasileira, 2000.

RIBEIRO, Luiz Cesar de Queiroz et al. O futuro das metrópoles: desigualdades e governabilidade. Rio de Janeiro: Revan, 2000.

RIBEIRO, Luiz Cesar de Queiroz et al. Dinâmica metropolitana e novos padrões de desigualdade social. São Paulo em perspectiva, São Paulo, v. 9, n. 2, p. 25-32, abr./ jun. 1995.

RIBEIRO, Luiz Cesar de Queiroz et al. Dos cortiços aos condomínios fechados: as formas de produção da moradia na cidade do Rio de Janeiro. Rio de Janeiro: Civilização Brasileira, 1997. 
ROLNIK, Raquel. Seminário Nacional Estatuto da Cidade + 10 anos, 2011. Disponível em: <http://escadaedesenvolvimento.wordpress.com/2011/02/07/ seminario-nacional-\%E2\%80\%9Cestatuto-da-cidade-10-anos-avancos-e-desafiosda-politica-urbana-e-dos-planos-diretores-participativos>. Acesso em 13 jul. 2011.

ROLNIK, Raquel; CYMBALISTA, R. (Org.). Instrumentos urbanísticos contra a exclusão social. Revista Pólis, São Paulo, v. 1, n. 29, p. 1-20, jan. 1997.

ROLNIK, Raquel et. al. Regulação urbanística e exclusão territorial. Revista Pólis, São Paulo, v. 1, s/n., p. 15-36, 1ª. ed. 1999.

SANTOS, Cláudio Hamilton S. Políticas federais de habitação no Brasil: 1964/1998. Brasília: IPEA, 1999. Disponível em: <http://www.ipea.gov.br/pub/td/td_99/ td_654.pdf>. Acesso em: 19 jan. 2011.

SANTOS JUNIOR, Orlando Alves. Reforma Urbana. Por um novo modelo de planejamento e gestão das cidades. Rio de Janeiro: FASE; UFRJ-IPPUR, 1995.

SANTOS, Milton. Técnica, espaço tempo: globalização e meio técnico científico informacional. São Paulo: Hucitec, 1994.

SANTOS, Milton. Por uma outra globalização: do pensamento único a consciência universal. Rio de Janeiro: Record, 2000.

SANTOS, Milton. A natureza do espaço: técnica e tempo: razão e emoção. São Paulo: EDUSP, 2002.

SANTOS, Milton. A urbanização brasileira. 5. ed., 1. reimpr. São Paulo: Editora da Universidade de São Paulo, 2008.

SAULE JUNIOR, Nelson; OSORIO, Letícia Marques. Direito à moradia: Relatório Nacional: 2003. Kenya: Unhabitat, 2003. Disponível em: <http://www.unhabitat. org/downloads/docs/2649_61742_03.05.20.Analisis\%20Brasil\%202003.doc>. Acesso em: 16 jan. 2011.

SAULE JÚNIOR, Nelson et al. (Org.) Assentamentos urbanos: Brasil século XXI os caminhos da sustentabilidade cinco anos depois da Rio 92. Rio de Janeiro: FASE, 1997.

SUNDFELD, Carlos Ari. O estatuto da cidade e suas diretrizes gerais. In: DALLARI, Adilson; FERRAZ, Sérgio (Org.). Estatuto da cidade - comentários à Lei Federal 10.257/2001. São Paulo: Malheiros, p. 45-60, 2003. 
VALLADARES, Lícia do Prado. A invenção da favela: do mito de origem à favela. com. Rio de Janeiro: FGV, 2005.

VASCONCELOS, J. A. M. de. Regularização fundiária e a urbanização de áreas faveladas em programas financiados pelo BNH. Rio de Janeiro: BNH, 1986. 